\title{
GÊNERO FEMININO: UM PANORAMA DA SITUAÇÃO DA MULHER NA SOCIEDADE
}

\section{ARTIGO ORIGINAL}

STUMPF, Katiusa ${ }^{1}$

STUMPF, Katiusa. Gênero feminino: Um panorama da situação da mulher na sociedade. Revista Científica Multidisciplinar Núcleo do Conhecimento. Ano 05, Ed. 06, Vol. 13, pp. 82-92. Junho de 2020. ISSN: 2448-0959, Link de acesso: https://www.nucleodoconhecimento.com.br/ciencias-sociais/genero-feminino

\section{RESUMO}

Numa abordagem do gênero feminino e de seu desenvolvimento no decorrer dos tempos, destacando aspectos no âmbito familiar, social e profissional, com esse trabalho objetivou-se apresentar um panorama da situação da mulher na sociedade contemporânea ressaltando questões como a violência (tortura e estupro), desigualdade profissional, prostituição, exposição de símbolos fálicos, necessidade de continuação dos projetos voltados para as políticas de igualdade de gênero, análise do desenvolvimento da menina desde os cuidados na família atravessando o processo de mocidade até sua maturidade, currículo pedagógico, literatura infantil, lutas feministas, valores éticos e morais, machismo mitológico, doutrinário e religioso. Metodologicamente contou-se com a pesquisa do tipo bibliográfico, tendo sido efetuada a leitura de diversos materiais bibliográficos para sua posterior análise e processo de construção desse artigo. Assim sendo, conclui-se que a mulher sofre discriminação devido à uma herança cultural onde diversos fatores contribuíram para a existência de tais preconceitos. Para finalizar defende-se o tratamento mais abrangente de tais assuntos pela mídia, pelo governo e pela sociedade como um todo, pois somente através do diálogo, da denúncia dos crimes e do apoio social e

\footnotetext{
${ }^{1}$ Mestre em Ciência da Informação - UFSC.
} 
governamental a sociedade pode evoluir ética e moralmente rumo a um novo panorama mais igualitário.

Palavras-chave: Gênero feminino, desigualdade de gênero, machismo, feminismo.

\section{INTRODUÇÃO}

Os diferentes períodos da história revelam acontecimentos sociais e culturais dos quais resulta a atual conjuntura social. De acordo com Célia Chaves Amaral (2005), há uma frase no livro de Simone de Beauvoir que as feministas costumam citar: "Não se nasce mulher, torna-se mulher". O que significa dizer que a mulher não é anatomicamente um destino e mostra como ela foi historicamente construída. Inspirado neste exemplo procura-se demonstrar um pouco do desenvolvimento e da formação da mulher na sociedade além de destacar as desigualdades existentes e algumas reflexões de mudanças no panorama situacional da mulher na atualidade.

O objetivo do trabalho, portanto, é analisar a situação da mulher na sociedade atual localizando as falhas no sistema social e sugerindo soluções para eliminar as desigualdades e discriminações de gênero.

Para isso utilizou-se como procedimento metodológico a técnica da pesquisa bibliográfica na organização dos documentos pesquisados. Através da busca e da localização de livros, teses, periódicos e outros materiais sobre questões pertinentes a situação da mulher na sociedade, efetuaram-se leituras, sumarização do conteúdo estudado além de fichamentos de citações e de resumos analíticos.

\section{REVISÃO DE LITERATURA}

Considerando que muitos autores contribuíram com estudos feministas e relacionados, a revisão de literatura proposta neste artigo encontra-se fundamentada em conteúdos relevantes para a reflexão e discussão do tema "gênero feminino". Parte dessa literatura foi produzida no contexto europeu. Assim sendo, Philippe Ariès (1978) observa que a partir do século XIV assistimos a uma degradação da mulher e 
de sua situação no lar quando ela perdeu o direito de substituir o marido ausente e seus atos passaram a ser considerados nulos pela justiça da época.

Angeli (2004), embasada em Maria I. S. Matos (2003), mostra alguns estudos sobre as diferenças biológicas entre homens e mulheres, suas habilidades e capacidades intelectuais, inclusive o papel social de cada um, ganharam destaque devido à valorização das ciências biológicas e da anatomia. Nesta época, surgiram as primeiras ilustrações da estrutura do esqueleto feminino destacando características tais como a fragilidade física, beleza, delicadeza, crânios pequenos e bacia larga. Acreditava-se que as mulheres possuíam tais características por serem dotadas de menores capacidades intelectuais e por terem como função natural à maternidade. Por isso, os médicos daquele tempo consideravam o sistema nervoso feminino extremamente instável e acreditavam que as mulheres poderiam sofrer problemas psíquicos se perturbadas por excessos de estudo, leituras, música e diversões noturnas como teatro e bailes.

Michelle Perrot (1988) afirma que as representações do poder das mulheres são um imenso tema de investigações históricas e antropológicas demonstrando que os preconceitos relativos às diferenças de gênero sexual existem há séculos e, apesar de muitos direitos femininos terem sido conquistados, tais preconceitos persistem geração pós-geração.

Em todas as culturas, mulheres sofreram e ainda sofrem com as diferenças e com a violência. Mary Del Priore (1997) aborda histórias trágicas de brasileiras indígenas vítimas do processo de colonização portuguesa (estupros, espancamentos, assassinatos...), mulheres que tiveram suas respectivas identidades ignoradas, que foram tratadas como não humanas. Mulheres negras arrancadas da África e trazidas como escravas para a América tendo como destino levar chibatadas e marcas de ferro quente no corpo. De acordo com a autora, milhares de mulheres existiram, mas não puderam viver nem amar, casando-se por obrigação fundamentada em interesses capitais, sem terem direito de estudar, servindo apenas para parir e criar, de modo a cumprir suas respectivas funções naturais. 
Zordan (2005) ressalta as crenças da Antiguidade onde as bruxas eram vinculadas à disputa com o diabo pelo poder do universo dentro de uma lógica patriarcal em que era inconcebível imaginar que a mulher, por si própria, tivesse a capacidade de curar e lançar malefícios sobre o corpo ou realizar certos fenômenos ditos "sobrenaturais"

Conforme Rene Menard (1985), a mitologia greco-romana agrega conceitos que avançam ao longo dos tempos através de preconceitos quase indestrutíveis. Alguns exemplos disso são os símbolos do homem e da mulher ainda bastante utilizados, inclusive para a identificação de banheiros públicos. O círculo com a cruz representando o espelho de Afrodite (Vênus), símbolo feminino e a flecha dirigida para o alto representando o escudo e a lança de Ares (Marte), símbolo do homem. Ou seja, o contraste entre a passividade e futilidade feminina perante a coragem audaciosa e poderosa do homem.

No ambiente brasileiro, ainda no fim do século XIX, os preconceitos dirigidos às mulheres eram publicados em jornais locais e nacionais. Em Desterro, atual Florianópolis, as mulheres eram retratadas como infiéis, vaidosas e ignorantes nas piadas dos jornais. No Jornal do Comércio de 1893:

-Um amigo pergunta ao outro:

-Por que razão Jesus, ao ressuscitar, mostrou-se em primeiro lugar a uma mulher?

-Porque queria que a notícia se espalhasse depressa (PRIORE, 1997, p.311)

Ou, ainda, em quadrinha no Jornal República, em 1892:

Deus criou o homem e ficou satisfeito.

Deus criou a mulher e sentiu-se remordido na sua santa consciência.

E então disse: 
A mulher será vaidosa, inconstante e pérfida.

Enganará o homem e o homem será infeliz.

E para consolá-lo, criou o cão (PRIORE, 1997, p.310).

Isso mostra como as desigualdades estão em todos os lugares. Estes preconceitos ainda existem de maneira forte e evidente. Nos dias atuais, a imprensa cotidiana mostra que as mulheres da Arábia Saudita são proibidas de dirigir automóveis, as mulheres do Egito sofrem mutilações genitais para não sentir prazer e, na Jordânia; o pai tem o direito de matar a filha se ela tiver relações sexuais antes do casamento. Sem falar das afeganistãs, escondidas sob seus véus longos e escuros, sob perversas condições de existência como mostrado no livro reportagem de Asne Seierstad (2006) e, ainda, das pobres meninas japonesas rejeitadas pela preferência masculina. As "frágeis" mulheres empunharam enxadas no campo, cuidaram do lar, da casa, lavaram e passaram, foram simples, humildes e companheiras sem receber em troca qualquer glória ou atenção. Outras foram tragadas pela prostituição, pelo engano, pela esperança de conseguir uma chance de viver dignamente.

No Brasil, delegacias policiais específicas foram criadas para descobrir e punir crimes contra as mulheres. Todavia, são milhares de casos de violência registrados e ainda são poucas as vítimas que procuram ajuda. A realidade está repleta de casos discriminatórios indicando que o dualismo sexual não reside na força e/ou na fragilidade de um ou de outro, mesmo que tenha se originado aí. O problema é o preconceito, a falta de valores éticos e/ou morais na sociedade como um todo, conforme esclarece Francisco das Chagas de Souza (2002):

O termo ética, então, recobre um fenômeno da existência social que nasce com a humanidade, a partir do momento em que o homem toma a consciência de seu ser com o outro. A ética, assim, está relacionada ao momento fundante do perceber-se e sentir-se em relação ao outro ser que é semelhante e que, portanto, deve também perceber-se como semelhante. Essa tomada de consciência de ser e de estar entre iguais 
exige a formulação de princípios que resguardem a individualidade e sua integridade no coletivo, concebendo a todos os de mesma origem como sendo iguais na relação com o mundo (SOUZA, 2002, p.17, grifo meu).

Esta definição reflete a importância de se falar sobre ética e conseqüentemente sobre direitos humanos; sabendo questionar os modelos sociais, políticos e econômicos que orientam as ações dos Estados e o cotidiano dos cidadãos. Podemos destacar aqui a abordagem do autor sobre individualidade e sua integridade no coletivo, pois esta necessidade humana exprime o desejo de todos por paz, democracia, liberdade e igualdade.

Valores foram perdidos e/ou desviados ou ainda não completamente aperfeiçoados no decorrer dos anos enquanto a conjuntura social se transformava e os seres humanos transformavam-se também.

Retomando a abordagem histórica, observa-se o desencadear de acontecimentos formadores do atual contexto social. Fustel de Coulanges (1998) trata sobre como a família se formou na cidade grega e romana antiga através da força do marido sobre a mulher, do pai sobre os filhos, com a autoridade paternal, ou marital. E logo o autor destaca o casamento como primeira instituição estabelecida pela 'religião doméstica'. $\mathrm{Na}$ sociedade antiga, o casamento representava uma complexa cerimônia religiosa onde, apos pronunciada a fórmula sacramental, o pai declarava 'dar' sua filha ao noivo e a sua nova religião.

O mesmo sentido de posse da mulher pelo homem é visto em algumas passagens bíblicas tais como: "Se uma jovem é dada por esposa a um homem e este descobre que ela não é virgem, então será levada para a entrada da casa de seu pai e a apedrejarão até a morte" (DEUTERONÔMIO, 22:20-21). "As mulheres têm de ser submissas aos vossos maridos" (I PEDRO, 3:1). "O homem não foi criado para a mulher, mas a mulher para o homem" (I CORÍNTIOS 11:9). "A mulher aprenda em silêncio com toda a submissão. Pois não permito que a mulher ensine, nem tenha domínio sobre o homem, mas que esteja em silêncio. Porque primeiro foi formado Adão, depois Eva" (I TIMÓTEO 2:11-13). 
A figura feminina é sempre mostrada de maneira inferior em relação à masculina. A bíblia relata a criação do homem em primeiro lugar e a mulher apenas como um complemento, além disso, a culpa pelo pecado original é atribuída à mulher e a maior parte das personagens em destaque são homens, inclusive os doze discípulos de Jesus. Beauvoir (1980) complementa:

A superioridade masculina é esmagadora: Perseu, Hércules, Davi, Aquiles, Lançarot, Duguesclin, Bayard, Napoleão, quantos homens para uma Joana D'arc; e por trás desta, perfila-se a grande figura masculina de São Miguel Arcanjo! [...] Eva não foi criada para si mesma e sim como companheira de Adão, e de uma costela dele; Rute não fez outra coisa senão encontrar um marido. Ester obteve a graça dos judeus ajoelhando-se diante de Assuero, e ainda assim não passava de um instrumento dócil nas mãos de Mardoqueu; Judite teve mais ousadia, mas ela também obedecia e sua proeza tem um vago sabor equívoco: não poderia compará-la ao triunfo puro e brilhante do jovem Davi. As deusas da mitologia são frívolas ou caprichosas e todas tremem diante de Júpiter; enquanto Prometeu rouba soberbamente o fogo do céu, Pandora abre a caixa das desgraças (BEAUVOIR, 1980, p.30).

O machismo preponderante na religião católica não só atingiu como também transformou a história desde os tempos da Inquisição, quando as bruxas consideradas hereges eram torturadas e queimadas vivas, até as maiores conquistas rumo a emancipação da mulher.

A hierarquia católica demonstra a sua visão machista perante a sociedade onde 0 escalão segue esta ordem: Papa, cardeal, bispo, padre, diácono, seminaristas e freiras. Tal ordem fica explícita em: "A cabeça do homem é Cristo, a cabeça da mulher é o homem e a cabeça de Cristo é Deus" (I CORINTIOS 11:9). Beauvoir (1980) ainda lembra que os anjos, de acordo com os teólogos não possuem sexo, mas possuem nomes masculinos e se apresentam na forma de jovens belos, enviados de Deus na Terra: O Papa, os bispos, etc. Por fim, salienta sobre a virgem Maria que acolhe de joelhos as palavras do anjo em seu sonho enquanto Maria Madalena prostra-se aos 
pés de Cristo e os enxuga com os seus próprios cabelos. Perrot (1988) define esta questão como 'feminismo cristão' onde as 'heroínas domésticas' têm o poder e o dever de agir bem.

Ruy Nunes (1978) relata como na Roma Antiga, por exemplo, a educação era destinada apenas aos heroico-patrícios que eram os proprietários rurais e guerreiros. Uma época em que as crianças permaneciam sob os cuidados maternos. Até certa idade, logo as meninas eram domesticadas $\mathrm{m}$ suas tarefas como cozinhar, costurar, cuidar do lar enquanto os meninos passavam a ser cuidados pelo pai que conduzia os estudos dos filhos. Como tratava-se de uma sociedade predominantemente agrícola, naquela época os meninos aprendiam a trabalhar com a terra, aprendiam esportes e a ler e a escrever e o básico de matemática. Os meninos eram ensinados a como se comportarem em sociedade. Naquele período, o patriotismo e a consciência histórica eram valores essenciais para o homem, por isso eles aprendiam e decoravam as leis da época. Ao passar dos quinze anos de idade, os meninos acompanhavam seus pais em sociedade. E mais tarde, aos dezesseis, assumiam a vida política ou a função militar.

Desde então resultam aptidões para determinados trabalhos. Ainda hoje, observamos meninos brincando com 'brinquedos de meninos' (bola, carrinho, jogos de montar, jogos eletrônicos de corrida, luta, tiro ao alvo...) e meninas com 'brinquedos de meninas' (bonecas, maquilagem infantil, mini-utensílios domésticos, jogos eletrônicos de bichinhos animados...). As roupas também seguem padrões semelhantes desde o enxoval do bebê com 'cores de meninos' como (azul, verde...) e 'cores de meninas' como (rosa, lilás...). Muitos pais, ainda hoje, por força da assimilação e cultivo desses valores, não percebem que estão reforçando e motivando futuras desigualdades de gênero que mais tarde aparecem, por exemplo, como desigualdades no trabalho.

Ora, se os meninos foram treinados a serem objetivos, rápidos e de raciocínio lógico, não serão eles destinados a trabalhos que requeiram tais habilidades? E se, por outro lado, as meninas tornaram-se aptas aos cuidados humanos, às sutilezas dos detalhes e à delicadeza e, portanto, a maior lentidão nos gestos; não estarão elas também prédestinadas a determinados trabalhos? Por que será que os cursos de ciências 
humanas estão cheios de mulheres enquanto as ciências naturais agregam em sua maioria, homens? As indústrias, por exemplo, destinam as tarefas de alta tecnologia para os homens enquanto as mulheres preenchem as vagas para trabalhos ou tarefas de menor qualificação e como se não bastasse também existe a hierarquia salarial onde, mais uma vez, as mulheres ficam em completa desvantagem. Tudo isso mostra como os preconceitos atualmente enfrentados nas relações de gênero não existem por mero acaso, mas por toda uma construção através da história. Independentemente de como isso tudo aconteceu, a dificuldade em superar os problemas existem e estão em todos os lugares, quer sejam no setor familiar, social ou profissional.

Depoimento de Domenico De Masi, relatado por Amaral (2005) ironiza a forma discriminatória com que as mulheres são tratadas no mundo do trabalho ao afirmar que, para ocupar postos de comando e situações de poder, o homem não precisa ser excepcional, mas a mulher, sim. Atualmente, mesmo ocupando cargos equivalentes, homens são mais bem remunerados que as mulheres. Isso tudo ocorre, além de diferenças entre tipos de trabalhos e profissões nos quais predominam as mulheres e que, por isso, são desvalorizados. Ferreira (2002 apud RASCHE, 2005) aborda sobre as diferenças de gênero dos profissionais deixando explícito na citação: "a enfermeira cuida dos doentes, a nutricionista da comida, a professora das crianças e a bibliotecária da arrumação da casa dos livros". Neste mesmo contexto Perrot (1988) afirma que o novo antifeminismo alimenta-se das conquistas das mulheres e suscita o fervor daqueles poucos que sonham com companheiras inteligentes, independentes e livres para trabalhar e cobrar seus direitos como salários justos e condições dignas.

Além destas e de muitas outras discriminações, as mulheres sofrem com a violência doméstica sendo muitas vezes manipuladas, violentadas e torturadas por seus companheiros. Cláudia Card (2006) diz que a violência doméstica é um problema global, sendo freqüentemente realizada através de processos de tortura.

estupro qualificado pela legislação brasileira só é caracterizado verdadeiramente como estupro se tiver ocorrido a penetração vaginal pelo pênis mediante ameaças e violência. Portanto, o sexo forçado oral e/ou anal não são considerados crimes de 
estupro, apenas como atentado violento ao pudor. Além disso, de acordo com Heleieth I. B Saffioti (1994) a violação sexual só é considerada como um ato violento quando praticada por estranhos ao contrato matrimonial, sendo aceita como normal quando ocorre no casamento.

Flávia de Mattos Motta (2006) fala sobre 'o estupro como morte', destacando, além dos casos em que as vítimas são assassinadas, também casos onde valores sociais, culturais, morais, implicam também, de alguma maneira, em morte. O estupro de guerra é destacado através de descrições de fotos que mostram soldados americanos estuprando mulheres iraquianas. Nesses casos, as conseqüências atuam não apenas no corpo e na psique de uma mulher violada, mas também no desonrar e humilhar um povo e uma etnia representados por mulheres vitimadas e, muitas vezes, fertilizadas pelo inimigo.

$\mathrm{Na}$ atual e global sociedade da informação, na qual a mídia poderia ser utilizada como ferramenta para denunciar e romper com os abusos e desigualdades sociais, acompanha-se dia-a-dia uma etapa manipulativa após a outra através dos meios de codificação e decodificação dos termos de linguagem utilizados na alienação geral do povo.

É importante, portanto, lembrar que a mídia possui um poder tão forte de designação, de influência cultural, que ela acaba por constituir a realidade social em que vivemos. Um bom exemplo disso é a cultura patriarcal que vem desde os tempos primórdios de um regime familiar onde o pai exerce direito absoluto sobre a família enquanto a mãe, pouco representa ou nada opina na tomada de decisões. Isso nada mais é do que a prevalência de uma cultura machista que a mídia, disfarçadamente, ou, em 'referência neutra', termina sustentando. Numa abordagem crítica da atualidade, Célia Chaves Amaral ressalta:

Nossas meninas estão sendo enganadas, entregues à própria sorte, vítimas da sanha de exploradores do sexo... Nossos corpos de mulher são exibidos e explorados, ontem na cozinha, dentro e fora de casa, no mundo virtual ou real. $\mathrm{O}$ mundo nos cria atraentes armadilhas de 
consumo e promessas de dinheiro fácil e entramos nesta onda sem refletir seu significado para o ser sujeito histórico (AMARAL, 2005, p.88, grifo meu).

É interessante destacar como a autora utiliza-se do plural na primeira pessoa para expressar a representação de todas as mulheres através das jovens expostas na mídia.

O mesmo ocorre com as estórias infantis. As crianças são 'moldadas' desde cedo com elementos fantasiosos do mundo encantado ao qual acreditam pertencer. No que diz respeito à menina:

Ela aprende que para ser feliz é preciso ser amada; para ser amada é preciso aguardar o amor. A mulher é a Bela Adormecida no bosque, Cinderela, Branca de Neve, a que recebe e suporta. Nas canções, nos contos, vê-se o jovem partir aventurosamente em busca da mulher; ele mata dragões, luta contra gigantes; ela acha-se encerrada em uma torre, um palácio, um jardim, uma caverna, acorrentada a um rochedo, cativa, adormecida: ela espera. [...] A suprema necessidade para a mulher é seduzir um coração masculino; mesmo intrépidas, aventurosas, é a recompensa a que todas as heroínas aspiram; e o mais das vezes não Ihes é pedida outra virtude senão a beleza (BEAUVOIR,1980,p.33).

De que adianta uma que outra matéria jornalística tratando dos conflitos de gênero com a devida importância, na tentativa de acabar com os preconceitos existentes se, ao mesmo tempo, todo final de semana, a TV brasileira está repleta de demonstrações contraditórias em programas de auditório como o do Faustão, do Gugu, do Luciano Huck e muitos outros cheios de mulheres figurativas, com o intuito de mostrar o corpo, a beleza física estereotipificada em modelos padrões a serem seguidos, em outras palavras, a figura feminina está sendo, na maioria das vezes, extremamente vulgarizada, servindo apenas de plano de fundo para um apresentador de TV, homem, com o instrumento do poder 'midiático' nas mãos: o microfone (símbolo fálico), do domínio do homem nos meios de comunicação e na sociedade em geral. 


\section{CONSIDERAÇÕES FINAIS}

Sintetizando esta discussão, considera-se, por fim, desejável do ponto de vista de crescimento da sociedade, que haja cada vez mais a intervenção de políticas governamentais públicas que atuem para o fim da crise cultural em que vêm se aprofundando as desigualdades entre homens e mulheres. No Brasil, uma iniciativa neste sentido foi à criação da Secretaria Especial de Políticas para Mulheres (SPM) implantada por Luiz Inácio Lula da Silva no primeiro dia de seu governo. Todavia, precisa-se de maiores investimentos em projetos de ação educacional em prol do fim das desigualdades de gênero, pois os recursos financeiros destinados para a área não têm atendido todas as demandas. Além disso, algumas mudanças no currículo pedagógico, que já estão acontecendo, devem ser reforçadas visando esclarecer as crianças sobre justiça social.

O mesmo se aplica à literatura infantil e infanto-juvenil que tem reformulado alguns clássicos com idéias atuais em versões mais livres de preconceitos e estereótipos padrões como Chapeuzinho Amarelo, por exemplo.

Também poderia se estender de forma mais rápida para políticas de acesso amplo à informação, através de redes municipais de bibliotecas públicas e comunitárias com serviços fartamente disponíveis em bairros e distritos, tanto nas áreas urbanas quanto rurais.

Conclui-se, portanto, que esta análise histórica mostra como as diferenças podem ser prejudiciais para o relacionamento das pessoas na sociedade e não apenas para as mulheres, apesar destas sofrerem mais. Além disso, elas precisam estar atentas ao fato de que não são completamente passivas e de que também participaram ativamente da construção histórica e da atualidade na qual encontram-se inseridas. A possibilidade de solução para os problemas consiste em diminuir gradativamente as desigualdades através da discussão do assunto, de sua divulgação pela mídia e da adoção de políticas de ampla difusão da informação em texto escrito, o que como um conjunto de ações auxiliaria o Estado, buscando, por fim, desenvolver um panorama 
social onde a ética e os valores morais voltados para o bem de todos, sem distinções, prevaleçam.

\section{REFERÊNCIAS}

AMARAL, Célia C. G. do. Debates de gênero: a transversalidade do conceito. Fortaleza. UFC, 2005.

ARIES, Philippe. História social da criança e da família. Rio de Janeiro: Zahar, 1978.

BEAUVOIR, Simone de. O segundo sexo. 2. ed. Rio de Janeiro. Nova Fronteira, 1980.

BÍBLIA. Português. Bíblia sagrada. Tradução de Padre Antônio Pereira de Figueredo. Rio de Janeiro: Encyclopaedia Britannica, 1980. Edição Ecumênica.

CARD, Claudia. Tortura em circunstâncias corriqueiras. In: MINELLA, L. S.; FUNCK, S. B. (Orgs.). Saberes e fazeres de gênero: entre o local e o global. Florianópolis: EDUFSC, 2006. p.51-63.

COULANGES, Fustel de. A cidade antiga. 4. ed. São Paulo: Martins Fontes, 1998.

MATOS, Maria I. S. de; SOIHET, Rachel (Orgs.). O corpo feminino em debate. São Paulo: Ed. da UNESP, 2003. Resenha de: ANGELI, Daniela. Uma breve história das representações do corpo feminino na sociedade. Revista Estudos Feministas: Florianópolis. V. 12, n.2, Maio/Ago. 2004.

MENARD, Rene. Mitologia greco-romana.. São Paulo: FITTIPALDI, 1985.

MOTTA, Flávia de Mattos. A morte e a janela: a idéia de morte em representações contemporâneas de estupro. In: MINELLA, L. S.; FUNCK, S. B.(Orgs.). Saberes e fazeres de gênero: entre o local e o global. Florianópolis: EDUFSC, 2006. p.89-103.

NUNES, Ruy. História da educação na antiguidade cristã. São Paulo: EPU/EDUSP, 1978. 
PERROT, Michelle. Os excluídos da história: operários, mulheres e prisioneiros. 2. ed. Rio de Janeiro: Paz e Terra, 1988.

PRIORE, Mary Del. (Org.). História das mulheres no Brasil. 2. ed. São Paulo: Contexto, 1997.

RASCHE, Francisca. Ética em bibliotecas públicas: representações de ética de profissionais da informação bibliotecários. Florianópolis, 2005. Dissertação (Mestrado em Ciência da Informação) - Programa de Pós-Graduação em Ciência da Informação UFSC, Florianópolis, 2005.

SAFFIOT, Heleieth I. B.; MUÑOS-VARGAS, Monica (Orgs.). Mulher brasileira é assim. Rio de Janeiro: NIPAS; Brasília: UNICEF, 1994.

SEIERSTAD, Asne. O livreiro de Cabul. 15. ed Rio de Janeiro: Record, 2007. 316p

SOUZA, Francisco das Chagas. de. Ética e deontologia: textos para profissionais atuantes em bibliotecas. Florianópolis: EDUFSC, 2002.

SOVIK, Levi. Et al. (Org.). Reflexões sobre o modelo de codificação/decodificação: uma entrevista com Stuart Hall. In: Hall, Stuart. Da diáspora: identidades e mediações culturais. Belo Horizonte: Editora UFMG; Brasília: Representação da UNESCO no Brasil, 2003.

ZORDAN, P. B. M. B.G. Bruxas: figuras de poder. Revista Estudos Feministas. Rio de Janeiro, v. 13, n. 2, 2005.

Enviado: Fevereiro, 2020.

Aprovado: Junho, 2020. 